\title{
Continuous manganese delivery via osmotic pumps for manganese-enhanced mouse MRI does not impair spatial learning but leads to skin ulceration
}

\author{
Dulcie A. Vousden ${ }^{\mathrm{a}, \mathrm{b}, *}$, Elizabeth Cox $^{\mathrm{a}}$, Rylan Allemang-Grand ${ }^{\mathrm{a}, \mathrm{b}}$, Christine \\ Laliberté $^{\mathrm{a}}$, Lily R. Qiu ${ }^{\mathrm{a}, \mathrm{c}}$, Zsuzsa Lindenmaier ${ }^{\mathrm{a}, \mathrm{b}}$, Brian J. Nieman ${ }^{\mathrm{a}, \mathrm{b}, \mathrm{d}}$, Jason \\ P. Lerch ${ }^{\mathrm{a}, \mathrm{b}}$ \\ ${ }^{a}$ Mouse Imaging Centre, The Hospital for Sick Children, 25 Orde Street, Toronto, ON, \\ M5T 3 H7, Canada \\ ${ }^{b}$ Department of Medical Biophysics, University of Toronto, 101 College Street Suite 15-701, \\ Toronto, ON, M5G 1L7, Canada \\ ${ }^{c}$ Institute of Medical Science, Faculty of Medicine, University of Toronto, 1 Kings College \\ Circle, Toronto, ON, M5S 1A8, Canada \\ ${ }^{d}$ Ontario Institute for Cancer Research, MaRS Centre, 661 University Ave, Suite 510, \\ Toronto, ON, M5G 0A3, Canada
}

\begin{abstract}
Manganese-enhanced magnetic resonance imaging (MEMRI) is a widely used technique in rodent neuroimaging studies. Traditionally, $\mathrm{Mn}^{2+}$ is delivered to animals via a systemic injection; however, this can lead to toxic effects at high doses. Recent studies have shown that subcutaneously implanted mini-osmotic pumps can be used to continuously deliver manganese chloride $\left(\mathrm{MnCl}_{2}\right)$, and that they produce satisfactory contrast while circumventing many of the toxic side effects. However, neither the time-course of signal enhancement nor the effect of continuous $\mathrm{Mn}^{2+}$ delivery on behaviour, particularly learning and memory, have been well-characterized. Here, we investigated the effect of $\mathrm{MnCl}_{2}$ dose and route of administration on a) spatial learning in the Morris Water Maze and b) tissue signal enhancement in the mouse brain. Even as early as 3 days after pump implantation, infusion of $25-50 \mathrm{mg} / \mathrm{kg} /$ day $\mathrm{MnCl}_{2}$ via osmotic pump produced signal enhancement as good as or better than that achieved 24 hours after a single $50 \mathrm{mg} / \mathrm{kg}$ intraperitoneal injection. Neither route of delivery nor $\mathrm{MnCl}_{2}$ dose adversely affected spatial learning and memory on the water maze. However, especially at higher doses, mice receiving $\mathrm{MnCl}_{2}$ via osmotic pumps developed skin ulceration which limited the imaging window. With these findings, we provide recommendations for route and dose of $\mathrm{MnCl}_{2}$ to use for different study designs.
\end{abstract}

Keywords: MEMRI, osmotic pumps, learning and memory, behavior, toxicity

${ }^{*}$ Corresponding author

Email address: dulcievousden@gmail.com (Dulcie A. Vousden)

Preprint submitted to NeuroImage

October 29, 2018 


\section{Introduction}

Manganese-enhanced magnetic resonance imaging (MEMRI) is an important tool for neuroanatomical and functional neuroimaging studies in animals [1, 2, 3. In its divalent form, manganese $\left(\mathrm{Mn}^{2+}\right)$ is paramagnetic and decreases $\mathrm{T} 1$ and T2 relaxation times 4, 1, 5. In the brain, $\mathrm{Mn}^{2+}$ is taken up by excitable cells via voltage-gated calcium channels [6]. It accumulates in active brain regions [7] and can be transported in axonal tracts [8, 9, 10. The uptake of $\mathrm{Mn}^{2+}$ provides excellent visualization of cytoarchitecture [1. Given this, MEMRI has many applications, including functional imaging of brain regions involved in specific behaviours 11, 12, neuronal tract tracing 13, 14, 15, 16, 17, 18, and imaging morphological changes through development [19], disease 20, 21, or during behavioural paradigms [22, 23, 24.

One of the main challenges of MEMRI is that $\mathrm{Mn}^{2+}$ can be cytotoxic at the high doses required to produce sufficient contrast 25. Indeed, it has been associated with different toxic effects in humans, dogs, rabbits, and rodents, including Parkinsonian-like symptoms 26, 27, liver failure 28, and cardiotoxicity 29. Traditionally, $\mathrm{Mn}^{2+}$ is delivered to animals via the salt manganese chloride $\left(\mathrm{MnCl}_{2}\right)$ either as a single intraperitoneal (IP), subcutaneous, or intravenous injection [25] or via fractionated doses, which have been shown to reduce toxicity [30, 31. However, repeated injections are stressful for the animal and so can be impractical for studies with many imaging time points. Moreover, even fractionated daily doses as low as $16 \mathrm{mg} / \mathrm{kg}$ /day have been associated with behavioural impairments such as decreased voluntary wheel running [12.

Recent studies have investigated an alternative approach for systemic $\mathrm{MnCl}_{2}$ delivery. In rodents, continuous infusion of $\mathrm{MnCl}_{2}$ via subcutaneously implanted mini-osmotic pumps has been shown to produce similarly enhanced tissue contrast in T1-weighted images with minimal behavioural abnormalities [32, 33, 12, 34. For instance, continuous infusion of $60 \mathrm{mg} / \mathrm{kg} /$ day $\mathrm{MnCl}_{2}$ produced high contrast after 5-8 days, with no impact on muscle strength or cortisone levels 34. Likewise, delivering a cumulative dose of $80 \mathrm{mg} / \mathrm{kg} \mathrm{MnCl}_{2}$ over 7 days produced sufficient contrast and avoided the impact on voluntary wheel running observed with IP delivery [12]. The use of mini-osmotic pumps therefore opens the possibility that MEMRI can be used for longitudinal neuroimaging studies without repeated injections and toxic effects.

Ideally, continuous infusion of $\mathrm{MnCl}_{2}$ would enable imaging across a range of time points. While continuous low doses of $\mathrm{MnCl}_{2}$ will eventually produce sufficient signal enhancement, often many days of infusion are required. Previous studies using osmotic pumps to deliver $\mathrm{MnCl}_{2}$ have typically delivered a high daily dose over a short period of time or a very low daily dose over a prolonged period 32. Additionally, with the exception of Sepulveda et al., [33, the few

Abbreviations: MEMRI: manganese enhanced magnetic resonance imaging, IP: intraperitoneal, $\mathrm{MnCl}_{2}$ : manganese chloride, $\mathrm{Mn}^{2+}$ :manganese, SNR: signal-to-noise ratio, ROI: region of interest, HC: hippocampus, OB: olfactory bulbs, CB: cerebellar cortex, TH: thalamus 
studies examining the use of osmotic pumps have imaged animals only at 2-3 timepoints 34, 32. A protocol that results in sufficient signal enhancement both immediately (2-4 days) after osmotic pump implantation and over longer time periods (1-3 weeks) has not yet been described, to our knowledge. To this end, we characterized the effect of continuous infusion of different doses of $\mathrm{MnCl}_{2}$ on tissue contrast over multiple time points.

One exciting potential application of longitudinal MEMRI studies is to monitor changes in functional activity or brain structure over time as animals learn a behavioural task [24, 22, 23]. A concern, though, is that $\mathrm{Mn}^{2+}$ will impair function in the brain areas in which it accumulates in high amounts, such as the hippocampus. Some studies demonstrate that single injections of $\mathrm{MnCl}_{2}$ do not impair choice accuracy on a hippocampal-dependent T-maze task 35, 36. However, the impact of continuous $\mathrm{MnCl}_{2}$ delivery on hippocampal learning and memory is not known. Manganese is also known to cause motor impairments, which may present a challenge for behavioural tasks with a motor component [37, 35. Given the diverse applications of MEMRI, it is important to characterize the time window in which continuous delivery produces satisfactory contrast while avoiding cytotoxicity. In this study, we sought to determine whether continuous infusion of $\mathrm{MnCl}_{2}$ via osmotic pumps is appropriate for longitudinal studies of brain anatomy and behaviour. To this end, in addition to examining signal enhancement, we investigated whether continuous infusion of $\mathrm{MnCl}_{2}$ impairs spatial learning and memory and/or gross motor abilities. Based on this data, we conclude with recommendations for when continuous infusion of $\mathrm{MnCl}_{2}$ is appropriate and when studies should use direct systemic injection instead.

\section{Materials \& Methods}

\subsection{Mice}

B6129SF1/Tac hybrid males (Taconic) age 10-12 weeks were used in this study. We used F1 hybrids because they learn the Morris Water Maze well and so would be sensitive to impairments caused by $\mathrm{MnCl}_{2}$ [38. All studies and procedures were approved by The Centre for Phenogenomics (TCP) Animal Care Committee in accordance with recommendations of the Canadian Council on Animal Care, the requirements under the Animals for Research Act, RSO 1980, and the TCP Committee Policies and Guidelines. Mice were maintained under controlled conditions (25 degrees C, 12/12 hour light/dark cycle) at the TCP in individually ventilated, sterile cages. Mice were provided a standard irradiated chow from Harlan (18\% Protein Rodent Diet, Harlan, Teklad Global, 2826 Latham Drive Madison, WI 53713) and sterile water ad libitum. At Day 0 , mice were assigned to one of 5 treatment groups: single intraperitoneal injection of vehicle (saline, IPVeh), single intraperitoneal injection of $50 \mathrm{mg} / \mathrm{kg}$ $\mathrm{MnCl}_{2}$ (IP50), osmotic pump delivering vehicle only (OPVeh), osmotic pump delivering $25 \mathrm{mg} / \mathrm{kg} /$ day $\mathrm{MnCl}_{2}$ (OP25), or osmotic pump delivering $50 \mathrm{mg} /$ $\mathrm{kg} /$ day $\mathrm{MnCl}_{2}$ (OP50, Fig. 1. Table 1). Group assignment was done to ensure the average animal weight was consistent between treatment groups. Mice were 


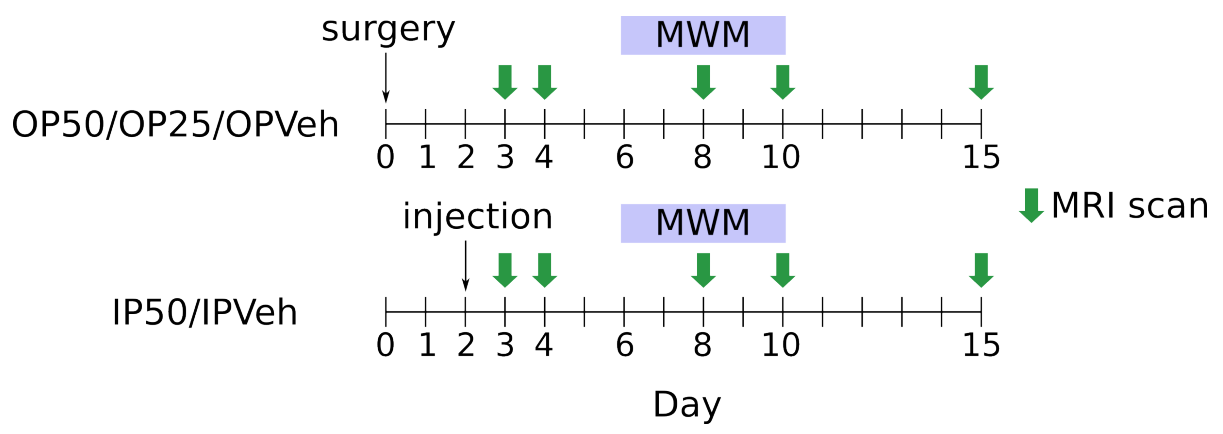

Figure 1: Experimental timeline. At Day 0, mice were randomly assigned to one of 5 treatment groups: single intraperitoneal injection of vehicle (IPVeh), single intraperitoneal injection of $50 \mathrm{mg} / \mathrm{kg} \mathrm{MnCl}_{2}$ (IP50), osmotic pump delivering vehicle only (OPVeh), osmotic pump delivering $25 \mathrm{mg} / \mathrm{kg} /$ day $\mathrm{MnCl}_{2}(\mathrm{OP} 25)$, or osmotic pump delivering $50 \mathrm{mg} / \mathrm{kg} /$ day $\mathrm{MnCl}_{2}$ (OP50). Mice in the osmotic pump groups were implanted on day 0 and given 2 days to recover before imaging. Mice receiving injections were injected on day 2. All mice were scanned on days $3,4,8,10$, and 15, and were trained on the Morris Water Maze (MWM) for 5 days starting on day 6. A probe test was performed one hour following the last trial on day 5 of training (day 10 of experimental timeline).

group housed prior to pump implantation and singly after implantation. To control for effects of housing, mice treated with intraperitoneal injections were also moved to single housing at the same time as surgically implanted animals.

\subsection{Manganese chloride solution}

\subsubsection{Manganese chloride preparation for intraperitoneal injections}

Manganese chloride tetrahydrate (Sigma Aldrich 13446-34-9) was dissolved in hydroclone purified water to yield a $300 \mathrm{mM}$ stock solution. This was subsequently diluted in sterile saline to yield a $30 \mathrm{mM}$ working solution that was used for intraperitoneal injections. An appropriate volume of $30 \mathrm{mM}$ working solution was injected to give a $50 \mathrm{mg} / \mathrm{kg}$ dose based on the animals' weight. Vehicle treated animals were given an equivalent volume of saline only.

\subsubsection{Manganese chloride preparation for osmotic pumps}

Manganese chloride tetrahydrate (Sigma Aldrich 13446-34-9) was dissolved in sterile saline to give a dosage of $25 \mathrm{mg} / \mathrm{kg} /$ day or $50 \mathrm{mg} / \mathrm{kg} /$ day based on the animals weight at the time of implantation. For vehicle treated animals the pumps were filled with an equivalent volume of sterile saline. 
Table 1: Number of mice trained and imaged in osmotic pump study

\begin{tabular}{|c|c|c|c|c|c|c|}
\hline \multirow[t]{2}{*}{ Treatment Group } & \multirow{2}{*}{$\begin{array}{l}\text { Number } \\
\text { trained }\end{array}$} & \multicolumn{5}{|c|}{ Number of scans used for each timepoint } \\
\hline & & Day 3 & Day 4 & Day 8 & $\begin{array}{l}\text { Day } \\
10\end{array}$ & $\begin{array}{l}\text { Day } \\
15\end{array}$ \\
\hline $\begin{array}{l}\text { Single Injection Vehicle } \\
\text { (IPVeh) }\end{array}$ & 6 & 5 & $6^{\dagger}$ & $6^{\dagger}$ & $6^{\dagger}$ & $6^{\dagger}$ \\
\hline $\begin{array}{l}\text { Single Injection } 50 \mathrm{mg} / \mathrm{kg} \\
\mathrm{MnCl}_{2} \text { (IP50) }\end{array}$ & 13 & 13 & $13^{\dagger}$ & $13^{\dagger}$ & $13^{\dagger}$ & $13^{\dagger}$ \\
\hline $\begin{array}{l}\text { Osmotic pump, Vehicle } \\
\text { (OPVeh) }\end{array}$ & 8 & $5^{7}$ & $4^{\ddagger}$ & $7^{\ddagger}$ & $5^{\ddagger}$ & $3^{\ddagger}$ \\
\hline $\begin{array}{l}\text { Osmotic pump, } 25 \\
\mathrm{mg} / \mathrm{kg} / \text { day } \mathrm{MnCl}_{2}(\mathrm{OP} 25)\end{array}$ & 10 & 10 & $\mathrm{q}^{8}$ & $7 \pi$ & 6 & $3^{* *}$ \\
\hline $\begin{array}{l}\text { Osmotic pump, } 50 \\
\mathrm{mg} / \mathrm{kg} / \text { day } \mathrm{MnCl}_{2}(\mathrm{OP} 50)\end{array}$ & 6 & 计 & 5 & $5^{\ddagger \ddagger}$ & 6 & $5^{\ddagger \ddagger}$ \\
\hline
\end{tabular}

\subsection{Implantation of mini-osmotic pumps}

Mice were implanted with Alzet mini-osmotic pumps model 1004 (DURECT Corporation, Cupertino, CA, USA) which continuously deliver reagent at a flow rate of $0.11 \mu \mathrm{L} /$ hour. Prior to implantation, the metal flow moderators were replaced with PEEK flow moderators to be MRI compatible using Loctite 454 cyanoacrylate glue (\#0008670). 48 hours before implantation, the pumps were primed with $\mathrm{MnCl}_{2}$ solution or saline by placing the filled pumps in sterile saline at 37 degrees Celsius. This ensured that the pumps were active when implanted.

For the surgeries, anaesthesia was induced using $4 \%$ isoflurane and maintained with $2 \%$ isoflurane. Prior to surgery, the mice received $500 \mu \mathrm{L}$ saline subcutaneously and an injection of meloxicam $(4 \mathrm{~mL} / \mathrm{kg})$ at the implantation site. Once anaesthetized, the animal's fur was shaved by the left or right flank. A small incision was made in the shaved skin, and a hemostat used to create a subcutaneous pocket for the pump. The pocket was large enough to allow

\footnotetext{
*1 scan excluded due to very low SNR

$\dagger$ Mice scanned to control for effects of anaesthesia

$\ddagger$ All mice were scanned at all timepoints but we were unable to obtain all images due to equipment failures

$\S 1$ mouse died in previous scan; equipment problems cause failure for other images

I A second mouse died in previous scan. 1 mouse excluded due to ulceration

$\|$ Problem with coil

**Equipment failure

$\dagger^{\dagger} 1$ mouse scanned but excluded from training due to ulceration

$\ddagger$ Problem with coil \& same mouse as above excluded due to ulceration
} 
some free movement of the pump, but was not so large that the pump could rotate. The pump was then inserted into the pocket, delivery portal first, and the wound closed with tissue glue. The mouse was allowed to recover in a warm cage and transferred to a cage with surgical bedding for recovery. Mice were treated with $2 \mathrm{mg} / \mathrm{kg}$ meloxicam ( $1 \mathrm{~mL}$ meloxicam in $9 \mathrm{~mL}$ saline) for 3 days following surgery. After surgery, mice were housed in a post-operative recovery cage for 3 days before being returned to a standard cage with regular bedding and nesting material.

\subsection{Imaging}

Whole brain images were acquired with a $7 \mathrm{~T}$ Varian scanner using in-vivo manganese-enhanced MRI. The MR acquisition protocol consisted of a 3D gradient echo sequence $(90 \mu \mathrm{m}$ isotropic resolution, $\mathrm{TR}=29 \mathrm{~ms}, \mathrm{TE}=5.37 \mathrm{~ms}, 7$ averages, 2 hour 48 min scan time). The mice were anaesthetized in an induction chamber using 3\% isoflurane 39, 40]. Mice were loaded onto custom built holders and imaged in vivo seven at a time using individual saddle coils at 3 , $4,8,10$, and 15 days post osmotic pump implantation. During the scan, the mice were maintained under $1 \%$ isoflurane anaesthesia delivered through the coil to the nose. The animals' breathing rates and temperature were monitored to maintain a respiratory rate of $20-40$ breaths per minute and temperature inside the magnetic bore of 29 degrees Celsius.

The mice that were injected intraperitoneally were injected once with either $\mathrm{MnCl}_{2}$ or saline 24 hours prior to the first scan (Day 2, see Figure 1). However, to control for the potential effect of anaesthesia and handling of the osmotic pump mice on subsequent behavioural testing, the IP mice were also scanned at the same time points as the OP mice. The number of images used at each time point is shown in Table 1. Although all mice were scanned at all time points, some images were excluded due to motion artefacts or low SNR (Table 11. Additionally, some mice were withdrawn from the study due to health effects (Figure 6). For each treatment group, there were at least 3 mice with high quality images at all of the time points.

In addition, 6 mice not in Table 1 were added to monitor health effects ( 3 in the OP25 group and 3 in the OP50 group). After the adverse health effects were identified, we tried slightly altering the osmotic pump implantation by making a deeper pocket for the pump. These mice were then monitored for adverse health effects but were not imaged or trained. This data was included in Figure 6 only.

\subsection{Image processing}

First, all acquired images were distortion-corrected to correct for small geometric distortions resulting from imaging in coils not in the centre of the magnetic field. To do so, coil-specific MR images of precision-machined phantoms were registered to a computed tomography (CT) scan of the same phantom. The resulting transformations were then applied to all acquired images in a

coil-specific manner. This process ensures that the anatomy and geometry of 
the MRI image accurately reflects that of the sample. There was no effect of coil position on image intensity.

After distortion correction, the images were non-uniformity corrected. In an MR image, the intensity of homogenous tissue should theoretically also be homogenous; however, there are localized non-uniformities in tissue intensity attributable to B1 variation [41. These were corrected using the N3 algorithm 42 .

Next, to compare the signal intensities in each region of interest, the MNI autoreg tools were used to rigidly align all the distortion and non-uniformity corrected images (henceforth input images) using a series of global rotations and translations [43. These transformations are intensity-preserving. Finally, the image intensities were normalized to the temporalis muscle from the same scan 34.

To automatically segment the resulting rigidly aligned images, the MAGeT (multiple automatically generated templates) Brain procedure was used with a pre-existing mouse brain atlas that segments the brain into 62 distinct regions [44, 45]. Briefly, in this process the input images were automatically segmented by non-linearly aligning the atlas to each of the input images in the study and then resampling the atlas labels [44, 46, 47. The result of this procedure was an individual atlas for each input image in the study segmenting it into 62 distinct regions [5].

\subsection{Statistical analysis of imaging data}

All analysis was performed using the $\mathrm{R}$ statistical language ( $\mathrm{R}$ Core Team, 2016, https://www.R-project.org) using the RMINC and lmerTest libraries (https://github.com/Mouse-Imaging-Centre/RMINC/) [48. First, the mean intensity (normalized to the temporalis muscle, as described above) was calculated for each region of interest (ROI) from the segmented atlas [45]. Then for each ROI, t-tests were used to compare the signal intensity in the IPVeh to the IP50 group, as well as to the OP25 and OP50 groups after 3 days of treatment. P-values were adjusted for multiple comparisons using the False Discovery Rate 49 .

Using the imaging data from only mice implanted with osmotic pumps, we also assessed the main effects and interaction between $\mathrm{MnCl}_{2}$ dose (vehicle, 25 $\mathrm{mg} / \mathrm{kg} /$ day, or $50 \mathrm{mg} / \mathrm{kg} /$ day) and days of treatment on signal intensity in each ROI. Specifically, linear mixed effects models were used to determine the effect of dose and days of treatment on the rate of increase in signal intensity for each ROI. Linear mixed effects models incorporate both fixed effects, like those included in traditional linear regression, as well as random effects [50. These models are particularly useful for longitudinal data and can handle a greater range of study designs (e.g. unbalanced designs) than traditional methods such as repeated measures ANOVAs. The general formula for a mixed effects model is:

$$
y_{i j}=\beta_{1} x_{1} i j+\ldots+\beta_{p} x_{p_{i j}}+b_{1_{i j}} z_{1_{i j}}+\ldots+b_{p_{i j}} z_{p_{i j}}+\epsilon_{i j}
$$


In this model $y_{i j}$ is the $j^{\text {th }}$ measurement of the dependent variable for mouse $i$. For the imaging data, this corresponds to the intensity in a particular ROI $y$ for mouse $i$ on day $j$. $\beta_{1} \ldots \beta_{p}$ are coefficients for the fixed effects or independent variables $x_{1_{i j}} \ldots x_{p_{i j}}$ and represent group-wise effects, as in traditional regression. In this study, we used fixed effects of days of treatment, dose, and the interaction between dose and days of treatment. The coefficients $b_{1_{i j}} \ldots b_{p_{i j}}$ are the coefficients for the random effects of each of the independent variables listed above. In this study, we included random intercepts for each mouse. $\epsilon_{i j}$ is the error term, which we assume to be independent and normally distributed. Therefore for a given ROI $y$, our model is:

$$
y_{i j}=\beta_{0}+\beta_{1} \text { Dose }+\beta_{2} \text { Days of Treatment }+\beta_{3} \text { Dose:Days of Treatment }+b_{1_{i j}}+\epsilon_{i j}
$$

$\beta_{1-3}$ are group-wise coefficients whereas $b_{1_{i j}}$ is a random intercept term for each mouse. This allows us to model the effect of dose and days of treatment on ROI intensity while accounting for the random subject-specific differences. To determine whether a particular fixed effect significantly improves the model, loglikelihood tests were performed comparing the model with the effect in question versus the model without that effect. For instance, to determine if there is a significant interaction between Dose and Treatment, we generated two models:

$$
\begin{gathered}
y_{i j}=\beta_{0}+\beta_{1} \text { Dose }+ \\
\beta_{2} \text { Days of Treatment }+b_{1_{i j}}+\epsilon_{i j} \\
y_{i j}=\beta_{0}+\beta_{1} \text { Dose }+\beta_{2} \text { Days of Treatment } \\
+\beta_{3} \text { Dose:Days of Treatment }+b_{1_{i j}}+\epsilon_{i j}
\end{gathered}
$$

and compared them using a log-likelihood ratio test. The log-likelihood ratio follows an approximately $\chi^{2}$ distribution in which the degrees of freedom is equal to the difference in the number of parameters in model 2 versus model 1. P-values were obtained using these $\chi^{2}$ distributions.

\subsection{Morris Water Maze training}

\subsubsection{Behavioural apparatus}

The water maze pool was $121 \mathrm{~cm}$ in diameter and made opaque using nontoxic white paint. During water maze training, mice learned to locate a 12 $\mathrm{cm}$ diameter hidden platform that was submerged $5-8 \mathrm{~mm}$ below the surface of the water. The platform location was constant over all trials, and distal cues were placed on the walls surrounding the pool to provide cues for navigation. The pool temperature was maintained at 25 degrees Celsius. The behaviour was recorded and tracked using the HVS Image Water 2020 Software using a camera mounted to the ceiling above the centre of the pool. 


\subsubsection{Behavioural training}

Behavioural training took place on Day 6 after pump implantation (Figure 1). Mice were handled for 2 minutes/day for 5 days prior to training. Mice were trained on the spatial version of the Morris Water Maze for 2 blocks of 3 trials/day for 5 days. The intertrial interval was 15 seconds and the interblock interval was 1 hour. Before the first trial on day 1 only, each mouse was placed on the platform for 15 seconds. For each training trial, one mouse was taken from its cage and carried to the pool in the experimenter's hands. The mouse was lowered into the pool with its nose facing the pool wall at one of 4 start locations (north, south, east, west). The start locations were chosen randomly, but kept consistent for all mice and always included the same number of locations close to versus far from the platform location. Immediately after placing the mouse in the pool, the experimenter hid from view and started the trial. The trial ended if the mouse found the platform in less than 60 seconds, after which the mouse was left on the platform for 15 seconds before being returned to a recovery cage on a heating pad. If the mouse did not find the platform within 60 seconds, it was guided to it and left there for 15 seconds. A probe test was performed 1 hour following the last trial on day 5. During the probe test, the platform was removed from the pool and the mice were given 60 seconds to search the pool. For each trial, the following metrics were automatically recorded: swim speed (metres/second), latency to reach the target platform (seconds), distance travelled to platform (metres), time spent in each pool quadrant, and time spent in a circular zone (20 cm radius) surrounding the target (or equivalent zone in non-target quadrants).

\subsection{Statistical analysis of behavioural data}

Separate linear mixed effects models were used to determine whether there was an interaction between day of training and treatment group (IPVeh, IP50, OPVeh, OP25, or OP50) on latency to reach the target platform and distance travelled to the platform. Fixed effects of days of training and treatment group were included along with random intercepts for each mouse. The variable treatment group was used instead of assessing the interaction between route of administration and $\mathrm{MnCl}_{2}$ dose because the cumulative dose of $\mathrm{MnCl}_{2}$ changed daily for OP mice whereas it was constant for IP mice. Additionally, for these behavioural metrics the data was fit with a second-order polynomial so that for the $i^{\text {th }}$ mouse on the $j^{\text {th }}$ day, the model for the behaviour metric $y$ was:

$$
\begin{array}{r}
y_{i j}=\beta_{0}+\beta_{1} \text { TreatmentGroup }_{i}+\beta_{2} \text { Day }_{i j}+\beta_{3} \text { Day }_{i j}^{2}+\beta_{4} \text { TreatmentGroup }_{i} \\
+\beta_{5} \text { TreatmentGroup }_{i} \text { Day }_{i j}^{2}+b_{i} \text { Mouse }_{i}+\epsilon_{i j}
\end{array}
$$

Here, $\beta_{0}$ to $\beta_{5}$ are fixed effects coefficients whereas $b_{i}$ is the coefficient for the random intercept for each mouse. Since we also wanted to assess whether route of administration (IP vs osmotic pump) and/or $\mathrm{MnCl}_{2}$ treatment $\left(\mathrm{MnCl}_{2}\right.$ vs. Vehicle) affected these behavioural metrics, separate mixed models were fit 
using these variables as fixed effects instead of treatment group. P-values were obtained by likelihood ratio tests of the full model with the effect in question against the model without that effect, using the $\chi^{2}$ approximation.

For the probe trial, ANOVAs were used to determine whether treatment group and separately, route of administration and/or $\mathrm{MnCl}_{2}$ treatment affected time spent in each pool quadrant or circular zone. For swimming data, we computed the mean swim speed on each day and used linear mixed effects model to test for an effect of treatment group, route of administration, or $\mathrm{MnCl}_{2}$ treatment.

\subsection{Health monitoring}

Mice were monitored daily for presence of adverse health side effects. Health data was analyzed in $\mathrm{R}$ using the survival library [51, 52. To assess the effect of treatment group on the likelihood of developing skin ulceration, Kaplan-Meier curves were generated and compared using pairwise log-rank tests.

\section{Results}

\subsection{Comparison of route of delivery of $\mathrm{MnCl}_{2}$ and effects on tissue contrast}

We first qualitatively compared the effect of route of $\mathrm{MnCl}_{2}$ delivery and $\mathrm{MnCl}_{2}$ dose on tissue contrast (Figure 2). Three days of infusion of $25 \mathrm{mg} /$ $\mathrm{kg} /$ day or $50 \mathrm{mg} / \mathrm{kg} /$ day $\mathrm{MnCl}_{2}$ both resulted in satisfactory contrast in the brain. The contrast appeared comparable to or better than that obtained with a single IP injection of $50 \mathrm{mg} / \mathrm{kg} \mathrm{MnCl} \mathrm{M}_{2}$ administered 24 hours prior to imaging (Figure 2). Although the cumulative dose of $\mathrm{MnCl}_{2}$ received by the IP50 and OP25/OP50 groups differs at this time point, the IP50 images were used as a reference as most MEMRI studies use single IP injections. A comparison between osmotic pump infusion and repeated IP injections has recently been published by Poole et al 34. Consistent with previous reports, brain regions in which manganese accumulates such as the hippocampus, olfactory bulbs, cerebellum, and thalamus were visible in scans of all mice treated with $\mathrm{MnCl}_{2}$, regardless of dose or route of delivery. Moreover, the contrast obtained in the OP50 group appeared qualitatively superior to that obtained in the IP50 and OP25 treated mice.

To analyze this quantitatively, we then compared the signal intensity (normalized to the temporalis muscle) obtained in 4 of the ROIs delineated in our atlas: the hippocampus (HC), olfactory bulbs (OB), cerebellar cortex (CB), and thalamus $(\mathrm{TH})$ [45]. In the IP50 mice, the signal intensity was significantly enhanced in the $\mathrm{OB}(\mathrm{t}=3.72, \mathrm{p}=0.009), \mathrm{HC}(\mathrm{t}=2.60, \mathrm{p}=0.029)$, and $\mathrm{CB}$ $(t=2.64, p=0.029)$ compared to IPVeh mice (Figure 3). There was no significant difference in the intensity of the thalamus between IP50 and IPVeh mice $(\mathrm{t}=0.98, \mathrm{p}=0.343)$. After the first post-operative scan ( 3 days after implantation), the signal intensity in the all 4 ROIs of OP25 mice was equivalent to that obtained in the IP50 group ( $>>0.05)$. In the OP50 mice, signal intensity was significantly higher in all 4 ROIs compared to those from the IP50 group 


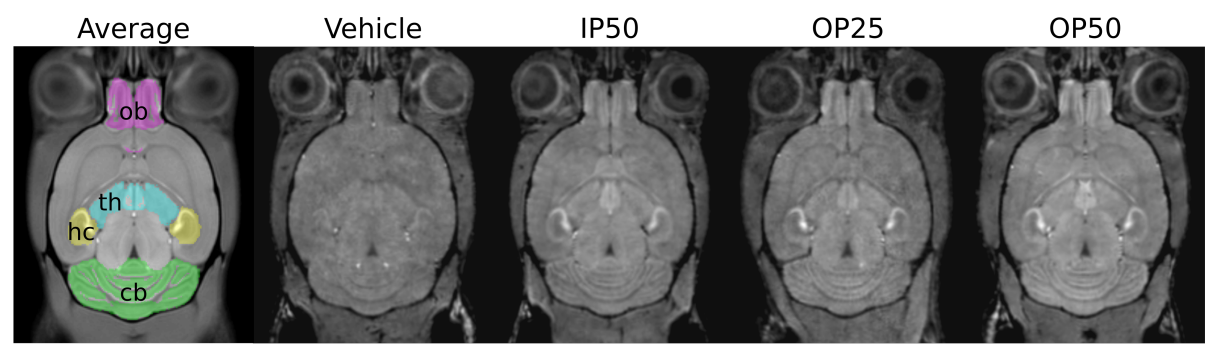

Figure 2: Comparison of dose and route of delivery of $\mathrm{MnCl}_{2}$ and effects on tissue contrast. Representative axial slices of either the study average image (Average) or single animals treated with saline vehicle injected intraperitoneally (Vehicle), $50 \mathrm{mg} / \mathrm{kg} \mathrm{MnCl}_{2}$ injected intraperitoneally (IP 50), $75 \mathrm{mg} / \mathrm{kg}$ (25 mg/kg/day for 3 days) of $\mathrm{MnCl}_{2}$ infused via osmotic pump (OP25), or $150 \mathrm{mg} / \mathrm{kg}\left(50 \mathrm{mg} / \mathrm{kg} /\right.$ day for 3 days) via osmotic pump (OP50). $\mathrm{MnCl}_{2}$ administration results in signal enhancement throughout the brain, most notably in the olfactory bulbs, hippocampus, and cerebellum. Images are normalized to the temporalis muscle.

(Figure 3. OP50 on day 3 vs. IP50 day 1: OB: $\mathrm{t}=3.27, \mathrm{p}=0.006, \mathrm{HC}: \mathrm{t}=3.24$, $\mathrm{p}=0.006, \mathrm{CB}: \mathrm{t}=2.34, \mathrm{p}=0.034, \mathrm{TH}: \mathrm{t}=2.86, \mathrm{p}=0.006)$.

Within the mice that received continuous $\mathrm{MnCl}_{2}$ via osmotic pumps, we also examined the effect of $\mathrm{MnCl}_{2}$ dose (Vehicle, $25 \mathrm{mg} / \mathrm{kg} /$ day, $50 \mathrm{mg} / \mathrm{kg} /$ day) and days of treatment on normalized signal intensity. There was a significant effect of both $\mathrm{MnCl}_{2}$ dose and days of treatment on normalized signal intensity, but no interaction between the two factors (Effect of $\mathrm{MnCl}_{2}$ Dose: HC: $\chi^{2}(2)=11.78, \mathrm{p}=0.003, \mathrm{CB}: \chi^{2}(2)=6.14, \mathrm{p}=0.046$, OB: $\chi^{2}(2)=15.23, \mathrm{p}=0.0005$, TH: $\chi^{2}(2)=11.03, \mathrm{p}=0.004$, Effect of Day: HC: $\chi^{2}(2)=22.63, \mathrm{p}=1.96 \mathrm{e}-6$, CB: $\chi^{2}(2)=22.53, \mathrm{p}=2.07 \mathrm{e}-6$, OB: $\chi^{2}(2)=5.49, \mathrm{p}=0.019$, TH: $\chi^{2}(2)=18.03, \mathrm{p}=2.17 \mathrm{e}-$ $5)$. In the OP25 group, signal intensity increased over time in all ROIs but peaked at 15 days of treatment. Increasing the dose delivered via osmotic pump to $50 \mathrm{mg} / \mathrm{kg} /$ day resulted in higher signal intensity in all ROIs (Figure 3 , statistics above). However, after 8 days of treatment (cumulative dose: $400 \mathrm{mg} / \mathrm{kg}$ ), the mean signal intensity began to plateau. In the $\mathrm{HC}, \mathrm{CB}$, and $\mathrm{TH}$, the mean signal intensity in OP25 mice never reached that of OP50 mice; even after 15 days of continuous infusion, the signal intensity in these ROIs was approximately equal to that observed in the OP50 mice after 3 days of infusion.

Figure 3 (following page): Time-course of signal enhancement in mice treated with continuous infusion of $\mathrm{MnCl}_{2}$. Top) Representative axial slices of single animals treated with 25 (OP25 - blue) or $50 \mathrm{mg} / \mathrm{kg}$ (OP50 - purple) daily $\mathrm{MnCl}_{2}$ delivered via subcutaneously implanted osmotic pumps and imaged 3, 4, 8, 10, and 15 days after implantation. Bottom) Normalized signal intensity in 4 regions of interest: hippocampus, cerebellar cortex, olfactory bulbs, and thalamus over imaging window. Single points are the mean signal intensities in vehicle treated mice (both IP and Pump: green) or mice treated with a single intraperitoneal injection of 50 $\mathrm{mg} / \mathrm{kg}$ manganese (IP50: red). Error bars are standard error of the mean. 


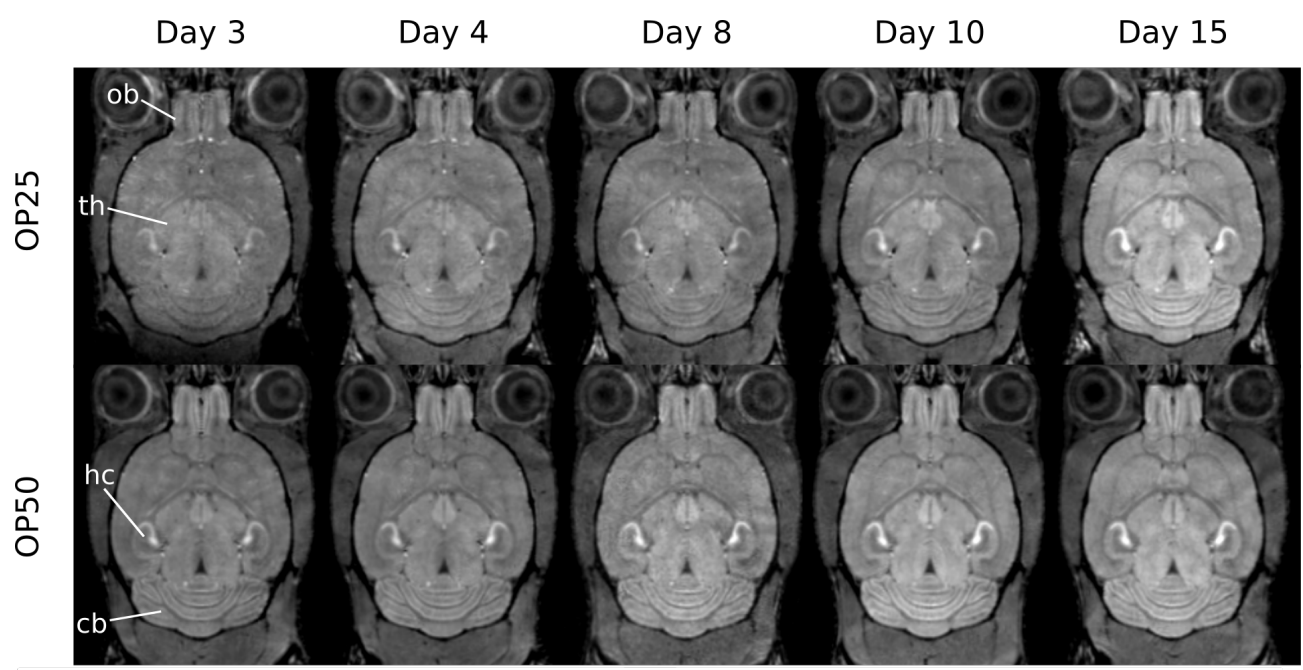

Hippocampus

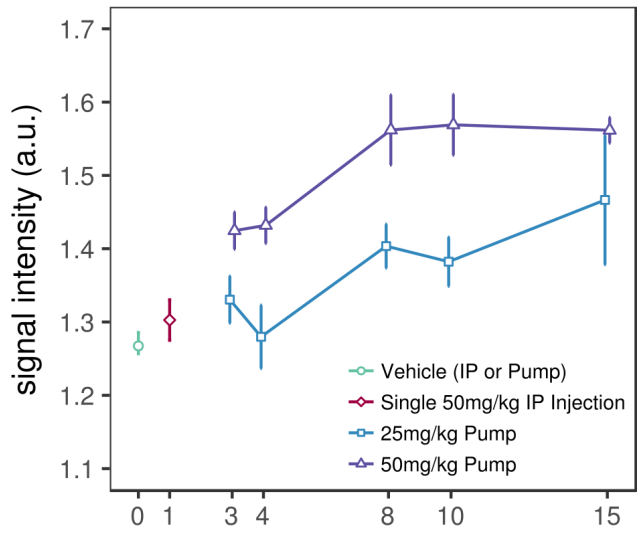

Olfactory Bulbs

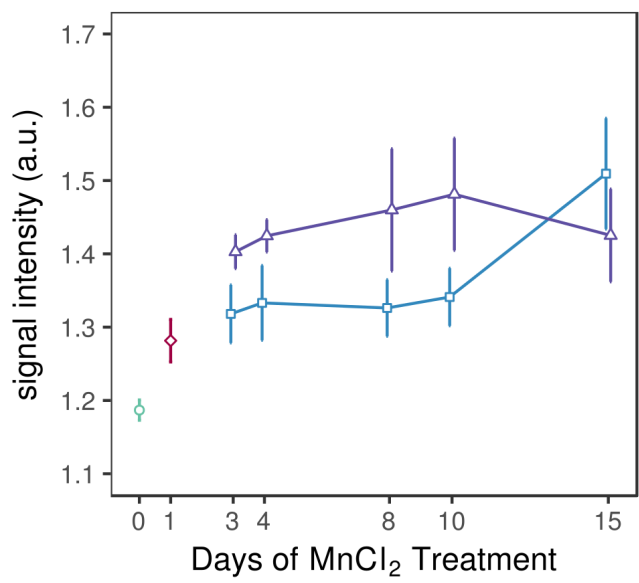

Cerebellar Cortex
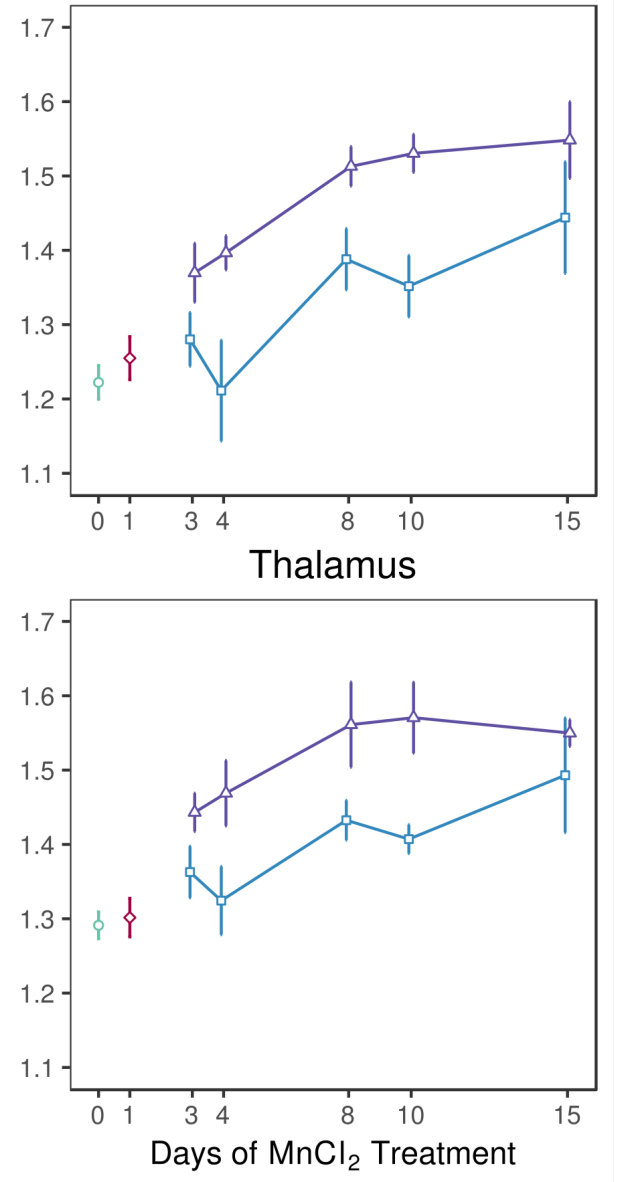


\subsection{Continuous $\mathrm{MnCl}_{2}$ administration does not impair spatial learning or mem- ory}

One concern of continuous $\mathrm{MnCl}_{2}$ treatment is that $\mathrm{Mn}^{2+}$ may disrupt brain function in areas such as the hippocampus where it preferentially accumulates 36. Although single injections of $16-80 \mathrm{mg} / \mathrm{kg} \mathrm{MnCl} \mathrm{Mn}_{2}$ do not impair hippocampus-dependent learning in rats, the impact of continuous infusion of $\mathrm{MnCl}_{2}$ on hippocampal dependent learning has not been investigated 35. Since MEMRI is increasingly being used for imaging studies involving behaviour and longitudinal studies of plasticity, we investigated whether osmotic pump implantation and/or $\mathrm{MnCl}_{2}$ delivery have adverse impacts of hippocampal dependent learning in mice.

First, we investigated whether the presence of an osmotic pump or $\mathrm{MnCl}_{2}$ treatment impacted swimming ability in the Morris Water Maze (MWM, Figure 4). $\mathrm{MnCl}_{2}$ has been associated with motor deficits, including gait abnormalities 12. We found that there was no effect of $\mathrm{MnCl}_{2}$ treatment on swim speed $\left(\mathrm{MnCl}_{2}\right.$ vs. Vehicle: $\left.\chi^{2}(4)=1.09, \mathrm{p}=0.29\right)$. However, there was an interaction between day of training and presence of osmotic pump (Pump vs IP: $\chi^{2}(1)=9.96, \mathrm{p}=0.002$ ). Of the mice implanted with pumps, those receiving 25 $\mathrm{mg} / \mathrm{kg} /$ day $\mathrm{MnCl}_{2}$ (OP25) swam more slowly on the first 2 days of training than the control animals receiving vehicle via IP (Treatment Group-Day interaction: $\chi^{2}(12)=15.0, \mathrm{p}=0.005$, OP25 vs. IPVeh: $\mathrm{t}=-2.254, \mathrm{p}=0.03$ (day 1 ) and $\mathrm{t}=-2.180, \mathrm{p}=0.03$ (day 2)). There was no difference between IPVeh and IP50 mice or between IPVeh and OP50 mice.

By day 3 this difference had normalized, and there was no effect of pumps, $\mathrm{MnCl}_{2}$ treatment, or specific treatment group on swim speed. Given the subtle impact of treatment group on swim speed at early time points, distance travelled to platform was used as a performance metric for spatial learning, as opposed to speed-dependent metrics such as latency to target.

Next we examined spatial learning and memory in the MWM. Neither $\mathrm{MnCl}_{2}$ treatment nor osmotic pump implantation adversely affected spatial learning or memory (Figure 5). While there was a significant interaction between treatment group and day on learning rate on the MWM $\left(\chi^{2}(8)=32.9, \mathrm{p}=6.27 \mathrm{e}-5\right)$, this was due to the fact that the OPVeh and OP25 treated mice performed better than the IPVeh treated mice on the first day (OP25 vs. IPVeh: $\mathrm{t}=-2.06, \mathrm{p}=0.04$ ) or first 2 days of training (OPVeh vs. IPVeh: $\mathrm{t}=-2.32, \mathrm{p}=0.02$ and $\mathrm{t}=-2.06$, $\mathrm{p}=0.05$ for day 1 and 2 respectively). By day 5 of training, there was no effect of treatment group on MWM performance. Likewise, in the probe test, mice spent significantly more time in the target quadrant than in non-target quadrants $(\mathrm{F}(1,90)=56.8, \mathrm{p}=3.63 \mathrm{e}-11)$, but there was no interaction effect between treatment group and quadrant on percent time spent in each quadrant (Figure 5. $\mathrm{F}(4,82)=0.72, \mathrm{p}=0.58)$. In addition, there were no brain areas where there was a significant correlation between the signal enhancement in scans acquired during training (day 8 and day 10) and subsequent performance on the probe test. 


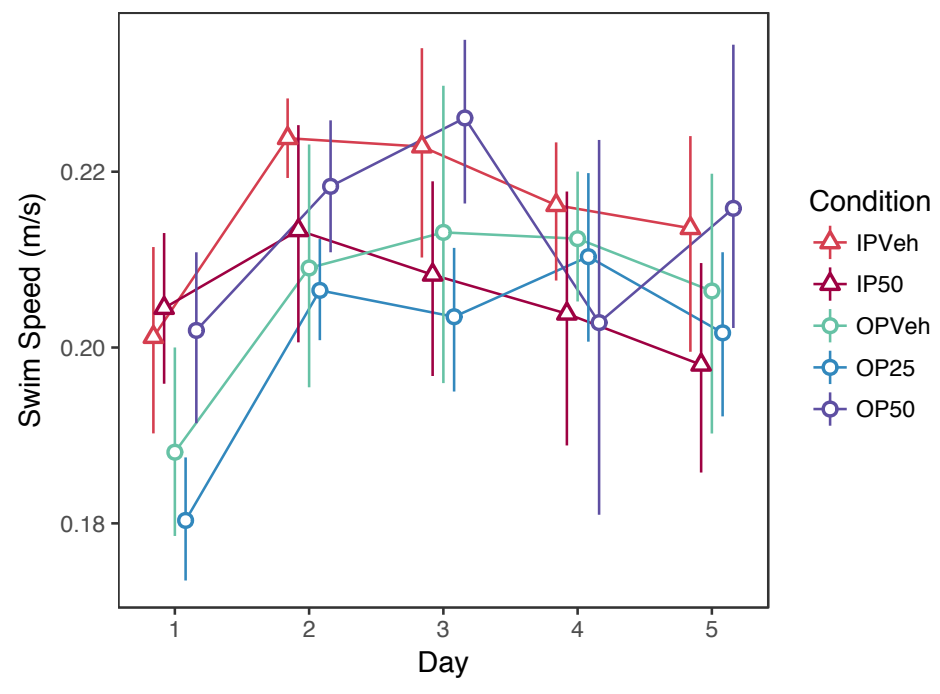

Figure 4: Average swimming speed in Morris Water Maze. Mice receiving $25 \mathrm{mg} / \mathrm{kg} /$ day $\mathrm{MnCl}_{2}$ or vehicle only swam significantly more slowly than all other groups of mice on day 1 and 2 of training. By day 3 of training, there was no effect of treatment group on swim speed. IPVeh $=$ Vehicle intraperitoneal injection, IP $50=$ single $50 \mathrm{mg} / \mathrm{kg} \mathrm{MnCl} \mathrm{M}_{2}$ injection, OPVeh=vehicle delivered via osmotic pump, OP25=25 mg/kg/day $\mathrm{MnCl}_{2}$ via osmotic pump, OP $50=50 \mathrm{mg} / \mathrm{kg} /$ day $\mathrm{MnCl}_{2}$ via osmotic pump

\section{Distance to Platform}

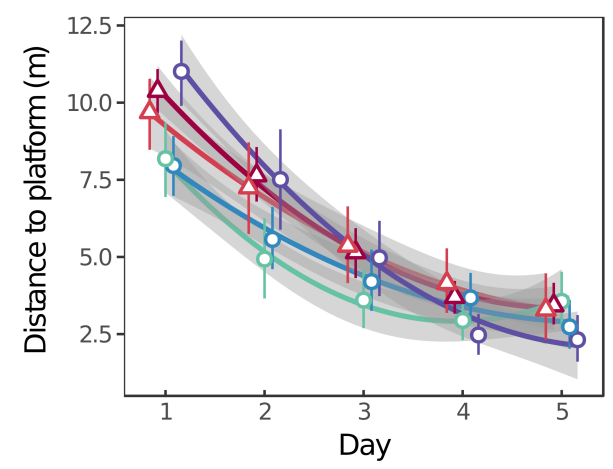

Probe Performance

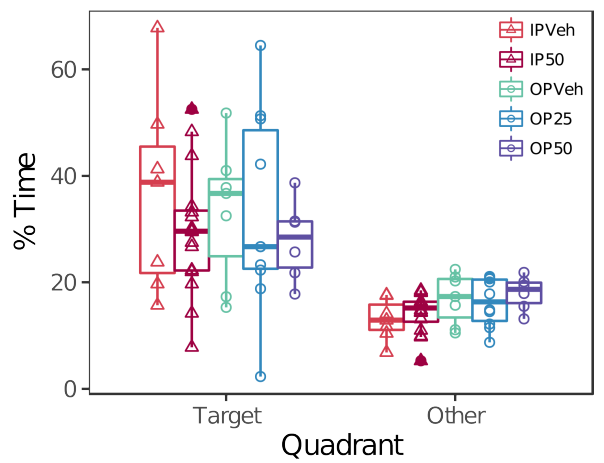

Figure 5: Effect of $\mathrm{MnCl}_{2}$ dose and route of delivery on spatial learning and memory. Mice were trained on a spatial version of the Morris Water Maze (MWM) for 6 trials/day over 5 days (left). Error bars are 95\% confidence intervals. There was no difference in performance on the MWM by day 5 training. Data was fit with a second order polynomial. Error bars are $95 \%$ confidence intervals. All groups of mice showed a preference for the target location (right). There was no significant effect of treatment group on quadrant preference. 


\subsection{Continuous $\mathrm{MnCl}_{2}$ administration leads to skin ulceration}

Although $\mathrm{MnCl}_{2}$ delivery did not impair learning and memory or swimming performance, we did observe significant health effects that have not been widely reported. Some mice that received $\mathrm{MnCl}_{2}$ via osmotic pump developed skin ulceration where the solution was being released from the pump (Fig. 6). This occurred even in the subset of mice not trained on the water maze, but did not develop in any of the control mice that received vehicle only via osmotic pump or intraperitoneally. In 4/17 cases, the ulceration was so severe that the mice had to be euthanized. Within the mice implanted with osmotic pumps, there was a significant effect of $\mathrm{MnCl}_{2}$ dose on the likelihood of developing tissue ulceration (Fig. 6. log-rank test, $\left.\chi^{2}(1)=11.3, \mathrm{p}=0008\right)$. In the OP50 mice, skin ulceration developed as early as 4 days post-implantation (cumulative dose of $200 \mathrm{mg} /$ $\mathrm{kg})$. After 14 days, all but 1 of the OP50 mice developed ulceration, which was significantly more than the vehicle treated $\left(\chi^{2}(1)=11.8, \mathrm{p}=0.0006\right)$ and OP25 mice $\left(\chi^{2}(1)=11.3, \mathrm{p}=0008\right)$. In the OP25 group, skin ulceration developed as early as 14 days after treatment, and by day 20 half the mice had developed ulcers, which was significantly more than the vehicle treated mice $\left(\chi^{2}(1)=4.3\right.$, $\mathrm{p}=0.00387)$. An autopsy was performed on 3 of the mice implanted with osmotic pumps. In all cases, there was no evidence of damage to the peritoneum, abdominal wall, or internal organs inside the abdominal cavity. There was also no sign of necrosis. However, there was a local immune reaction internally at the infusion site of the pump.

Within the mice that were injected intraperitoneally with $\mathrm{MnCl}_{2}, 3(23 \%)$ developed scabs at the injection site; however these resolved on their own and were not as severe as the skin ulceration observed in the mice implanted with osmotic pumps. Since the scabbing resolved, this data was not included in the Kaplan-Meier curves.

\section{Discussion}

MEMRI is a powerful tool for in vivo imaging of brain anatomy and cytoarchitecture, for neuronal tract tracing, and for functional imaging of brain activity in rodent models 2, 3. However, in longitudinal studies, challenges still remain in optimizing tissue contrast while avoiding $\mathrm{Mn}^{2+}$ toxicity. Here, we evaluated the tissue contrast obtained using continuous infusion of $\mathrm{MnCl}_{2}$ via subcutaneously implanted mini-osmotic pumps and compared it to that obtained with a single intraperitoneal injection. Additionally, we investigated whether continuous $\mathrm{MnCl}_{2}$ infusion was associated with adverse health outcomes and/or impairments in hippocampus-dependent learning and memory and/or gross motor abilities. We found that 3 days of delivery of $25 \mathrm{mg} / \mathrm{kg} /$ day or $50 \mathrm{mg} / \mathrm{kg}$ /day of $\mathrm{MnCl}_{2}$ via osmotic pumps produced signal enhancement that was similar or better than a single $50 \mathrm{mg} / \mathrm{kg}$ IP injection. Neither continuous infusion of $\mathrm{MnCl}_{2}$ nor the osmotic pump implantation itself was associated with spatial learning and memory deficits. However, at high doses, mice receiving $\mathrm{MnCl}_{2}$ via osmotic pumps developed skin ulcerations, which limited the timeframe in which mice could be imaged. 

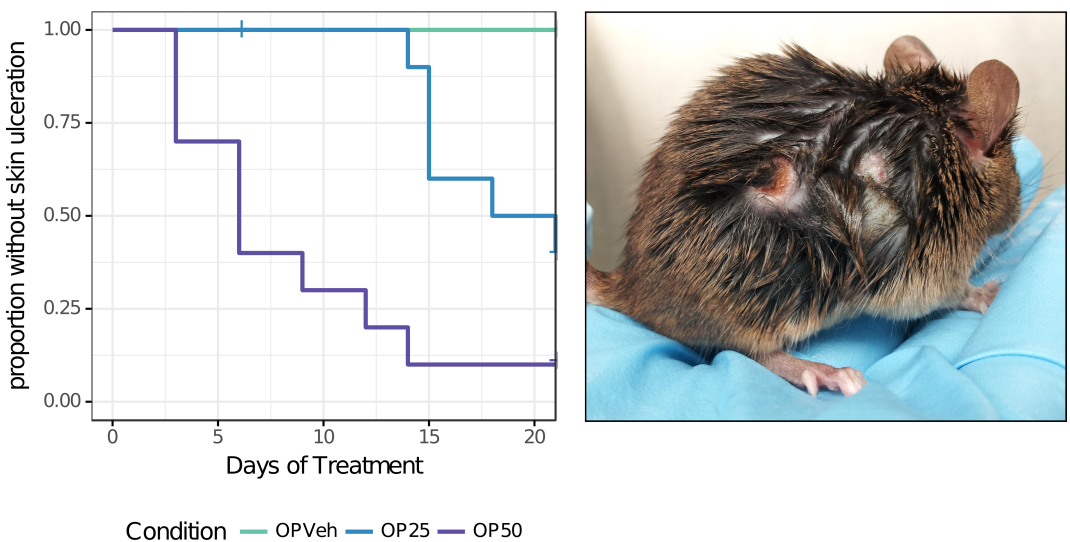

Condition - OPVeh - OP25 - OP50

Figure 6: $\mathrm{MnCl}_{2}$ treatment is associated with tissue ulceration. (left) Kaplan-Meier survival curves showing proportion of mice without skin ulceration after each day of treatment. None of the mice treated with vehicle only developed skin ulceration. After 9 days of treatment, all mice treated with $50 \mathrm{mg} / \mathrm{kg} /$ day $\mathrm{MnCl}_{2}$ had developed tissue ulceration. (right) A photo showing an example of skin ulceration where osmotic pump releases $\mathrm{MnCl}_{2}$ solution.

\subsection{Impact of route of delivery and dosage on tissue contrast}

We compared the signal intensity obtained when mice were treated with manganese either intraperitoneally $(1 \times 50 \mathrm{mg} / \mathrm{kg}$ injection) or via mini-osmotic pump $(25 \mathrm{mg} / \mathrm{kg} /$ day or $50 \mathrm{mg} / \mathrm{kg} /$ day $)$. After three days of $25 \mathrm{mg} / \mathrm{kg} /$ day infusion $(75 \mathrm{mg} / \mathrm{kg}$ cumulative dose), the contrast obtained in MR images of the brain was comparable to that obtained with a single $50 \mathrm{mg} / \mathrm{kg}$ injection. This is consistent with a previous study showing that a higher cumulative dose is required to produce the same contrast when $\mathrm{Mn}^{2+}$ is delivered subcutaneously via osmotic pump versus intraperitoneally 34. As discussed by Poole et al, this is likely because the peak plasma concentration of $\mathrm{Mn}^{2+}$ is lower when it is delivered subcutaneously, due to partial loss of $\mathrm{Mn}^{2+}$ into the tissue by diffusion and slow diffusion of $\mathrm{Mn}^{2+}$ into the bloodstream [53, 34 .

The signal enhancement obtained with $50 \mathrm{mg} / \mathrm{kg} /$ day $\mathrm{MnCl}_{2}$ began to plateau after 8 days of continuous infusion, at which point the mice had received a cumulative dose of $400 \mathrm{mg} / \mathrm{kg} \mathrm{MnCl}$. Conversely, the signal enhancement continued to increase beyond 8 days in mice receiving $25 \mathrm{mg} / \mathrm{kg} /$ day and peaked at day 15 when the mice had received a cumulative dose of $375 \mathrm{mg} / \mathrm{kg}$. Again, this is consistent with Poole et al., who observed that signal enhancement did not change between 5-8 days when mice received $60 \mathrm{mg} / \mathrm{kg} /$ day, or a cumulative dose of 300-480 mg/kg [34. Likewise, another study showed that the decrease in $\mathrm{T} 1$ relaxation produced by $30 \mathrm{mg} / \mathrm{kg} /$ day $\mathrm{MnCl}_{2}$ delivery plateaus after $8_{-}^{-}$ 10 days, or a cumulative dose of $240-300 \mathrm{mg} / \mathrm{kg}$ 33. Together these studies suggest that administering a cumulative dose greater than $400 \mathrm{mg} / \mathrm{kg} \mathrm{MnCl}_{2}$ is unlikely to result in further signal enhancement.

Delivery of $50 \mathrm{mg} / \mathrm{kg} /$ day $\mathrm{MnCl}_{2}$ resulted in superior signal enhancement 
after 3-10 days of treatment in all ROIs examined, consistent with prior reports that infusing a higher concentration of $\mathrm{MnCl}_{2}$ over a shorter time period produces improved contrast [32. After 15 days of $\mathrm{MnCl}_{2}$ delivery, the signal enhancement in the olfactory bulbs was equivalent between mice treated with $25 \mathrm{mg} / \mathrm{kg} /$ day and $50 \mathrm{mg} / \mathrm{kg} /$ day $\mathrm{MnCl}_{2}$. This suggests that some brain areas reach a saturation point sooner than others, at which point further $\mathrm{Mn}^{2+}$ delivery does not increase signal intensity. As suggested by Poole et al., the saturation in intensity may be because the MRI signal is not directly proportional to the total amount of $\mathrm{Mn}^{2+}$ in the brain [34. As they note, $\mathrm{Mn}^{2+}$ is sequestered by the mitochondria, and efflux of $\mathrm{Mn}^{2+}$ from the brain is very slow. Moreover, over $97 \%$ of the sequestered $\mathrm{Mn}^{2+}$ is bound to proteins [54. Thus it is possible that additional $\mathrm{Mn}^{2+}$ is accumulating, but that it is being sequestered in water-free macromolecular pockets and thus cannot contribute to the MRI signal 34. Additionally, $\mathrm{Mn}^{2+}$ influx increases in more active regions via a $\mathrm{Ca}^{2+}$-dependent mechanism [55, 34]. Brain-wide variations in neural activity and in $\mathrm{Mn}^{2+}$ efflux may contribute to the differences in saturation.

In the other ROIs (HC, TH, CB), even after 15 days, the contrast obtained in mice treated with $25 \mathrm{mg} / \mathrm{kg}$ day of $\mathrm{MnCl}_{2}$ did not reach that of mice treated with $50 \mathrm{mg} / \mathrm{kg} \mathrm{MnCl}_{2}$. This finding is in agreement with a recent study by Poole et al. showing that even with 8 versus 5 days of $\mathrm{MnCl}_{2}$ administration, the contrast obtained in mice treated with $30 \mathrm{mg} / \mathrm{kg}$ day of $\mathrm{MnCl}_{2}$ did not reach that of mice treated with $60 \mathrm{mg} / \mathrm{kg}$ day 34. Both these studies are consistent with studies showing that increasing the driving gradient produced by the difference in $\mathrm{Mn}^{2+}$ concentration between the brain and CSF leads to an increase in $\mathrm{Mn}^{2+}$ uptake [30].

\subsection{Use of MEMRI in studies of learning and memory}

MEMRI is increasingly being used for behavioural studies examining functional activity and plasticity in response to external stimuli. For instance, in vivo MEMRI was used to show that hippocampal volume changes during the mouse estrus cycle, and that this influences spatial learning 24]. MEMRI has also been used to monitor hippocampal plasticity in response to spatial learning and environmental enrichment [22, 23]. While these studies delivered $\mathrm{MnCl}_{2}$ via intraperitoneal injection, continuous delivery of $\mathrm{MnCl}_{2}$ via osmotic pumps is increasingly being used to bypass adverse side effects when when a high cumulative dose of $\mathrm{Mn}^{2+}$ is required [33, 32, 12, 34. While studies in rats show that hippocampal learning in the T-maze or delayed-match-to-sample water maze is not impaired after a single injection of $80 \mathrm{mg} / \mathrm{kg} \mathrm{MnCl}_{2}$, the impact of continuous treatment of $\mathrm{MnCl}_{2}$ on hippocampal learning has not been established [35, 36. Given the potential of MEMRI for longitudinal imaging studies, we sought to determine whether continuous delivery of $\mathrm{MnCl}_{2}$ or osmotic pump implantation itself affected hippocampal-dependent learning and memory. There was no impact of route of delivery or dose of $\mathrm{MnCl}_{2}$ on spatial learning and memory in the Morris Water Maze (MWM). In fact, OPVeh and OP25 mice performed better at this task on the first 2 days of training; however by the end of training and the probe test, all groups showed a strong memory for the 
target location. This implies that continuous delivery of $\mathrm{MnCl}_{2}$ can be used in studies of hippocampal-dependent learning and plasticity.

Previous studies demonstrate that $\mathrm{MnCl}_{2}$ does not alter grip strength 34, but can result in subtle alterations in gait 33 and impaired coordination on the rotarod 37. For this reason, before examining the effect of $\mathrm{MnCl}_{2}$ on spatial learning behaviour, we first analyzed whether mice receiving $\mathrm{MnCl}_{2}$ through osmotic pumps had altered swimming behaviour. Two groups of mice implanted with osmotic pumps (OPVeh and OP25) swam slower on day 1 of training than the other groups (IPVeh, IP50, and OP50). However, there was no difference in swim speed on day 5 of training. This is consistent with rat studies showing that a single dose of $\mathrm{MnCl}_{2}$ does not impair baseline locomotor activity or swim speed [56, 36. Since the mice receiving the highest dose of $\mathrm{MnCl}_{2}$ via osmotic pumps were unaffected, we suspect this was due to individual differences between mice; however, it highlights the importance of choice of metric (distance vs. latency) in studies of learning and memory and the importance of testing the impact of pump implantation alone in MEMRI studies incorporating behaviour.

Although swimming is not a common natural activity for mice, it has been demonstrated to be a sensitive test of motor coordination in both wildtype mice and in mouse models of neurological disease, such as Huntingtons and ataxia [57. Some studies show that mice with deficits on non-swimming motor tasks such as the rotarod and balance beam also have swimming deficits, suggesting swimming is viable alternative test for motor coordination [58, 59]. Nevertheless, there are other motor behaviours that were not tested by assessing swimming ability, including skilled reaching and grip strength. While Poole et al. did not observe changes in grip strength in mice treated with $480 \mathrm{mg} / \mathrm{kg}$ $\mathrm{MnCl}_{2}$, Sepulveda et al. do report subtle alterations in gait following $\mathrm{MnCl}_{2}$ treatment. While our visual assessment of locomotor activity was normal, we cannot exclude the possibility that $\mathrm{MnCl}_{2}$ treatment had more subtle effects on motor behaviour than were assessed here.

\subsection{Adverse health outcomes}

An unfortunate finding of this study was that continuous $\mathrm{MnCl}_{2}$ delivery with osmotic pumps is associated with skin ulceration at the infusion site. Importantly, this was not due to the pump implantation, as none of the mice receiving vehicle solution (saline) through the pump developed similar symptoms. Onset of ulceration was more rapid in mice receiving a higher dose of $\mathrm{MnCl}_{2}$ and likely arose from skin irritation due to $\mathrm{Mn}^{2+}$ exposure. Aside from one report of local inflammation/ulceration at the pump infusion site after 3 weeks of infusion of $30 \mathrm{mg} / \mathrm{kg} \mathrm{MnCl}_{2}$ (cumulative dose of $630 \mathrm{mg} / \mathrm{kg}$ ) 33, this outcome has not been reported in previous studies using osmotic pumps for $\mathrm{MnCl}_{2}$ delivery, and the onset of this ulceration has not been characterized. $\mathrm{MnCl}_{2}$ is known to be a potential skin irritant and can promote itchiness, which could lead to further irritation (Sigma SDS and 60]). Although some minor skin irritation can be observed when $\mathrm{MnCl}_{2}$ is given intraperitoneally, this irritation typically resolves quickly. It is likely that the continuous exposure to an irritant at the pump infusion site prevents the ulceration from resolving. For 
studies using continuous delivery of $\mathrm{MnCl}_{2}$, the dose and imaging time points must be carefully optimized and animals should be monitored for this adverse health outcome.

\subsection{Factors influencing choice of route of delivery for longitudinal MEMRI studies}

Continuous delivery of $\mathrm{MnCl}_{2}$ produces enhanced tissue contrast without impairing hippocampus dependent learning and memory. However, at high cumulative doses, mice developed skin ulceration at the infusion site which limits the time window in which the animals can be imaged. When designing MEMRI studies, it is important to choose a route and dose of $\mathrm{MnCl}_{2}$ delivery that suits the duration of study and number of imaging time points. Factors such as stress from repeated injections, stress from surgical implantation, and duration of post-operative single housing must also be considered when determining the appropriate route of administration. We found that when mice are given 50 $\mathrm{mg} / \mathrm{kg} /$ day $\mathrm{MnCl}_{2}$ via osmotic pump, the useable imaging window is only from day 3 to day 5 . It is difficult to image earlier than 3 days post-surgery, as the implantation site needs to heal. After 5 days of $\mathrm{MnCl}_{2}$ delivery and a cumulative dose of $250 \mathrm{mg} / \mathrm{kg} \mathrm{MnCl}_{2}$, there is a high risk of skin ulceration, which can require the mice to be euthanized. However, as others have shown 34, 32 delivering $\mathrm{MnCl}_{2}$ via osmotic pumps does allow for a higher cumulative dose than would be possible with a single bolus injection and does so without the stress of repeated injections. This means that higher-dose infusion via pumps is best suited for studies of rapid plasticity 24] or for functional imaging studies where a high cumulative $\mathrm{MnCl}_{2}$ dose is desired.

The useable imaging window for mice receiving $25 \mathrm{mg} / \mathrm{kg} /$ day is approximately 3-14 days. The $\mathrm{Mn}^{2+}$-induced signal enhancement does improve over the course of this period, but is significantly better than vehicle control as early as 3 days after implantation in some ROIs. However, after 14 days, nearly all the animals in our study had developed skin ulceration, which limits the imaging window. Based on our study, delivery of $25 \mathrm{mg} / \mathrm{kg} /$ day of $\mathrm{MnCl}_{2}$ is best suited to studies where mice are imaged at several time points over a $\sim 10$ day window. For instance, this approach could be used for short term studies of plasticity [22] but is ill-suited for long term imaging designs [23. In our view, studies with single imaging points and longer-term studies with less frequent imaging time-points are better performed using systemic injections of $\mathrm{MnCl}_{2}$.

An alternative approach is to use even lower doses of $\mathrm{MnCl}_{2}$ than studied here and wait for sufficient accumulation. For instance, Mok et al. infused 180 $\mathrm{mg} / \mathrm{kg}$ of $\mathrm{MnCl}_{2}$ over 14 days ( $13 \mathrm{mg} / \mathrm{kg} /$ day). However, this approach does not produce sufficient contrast at earlier time points, and so is limited to studies that can tolerate long exposure to $\mathrm{MnCl}_{2}$ before imaging. One consideration in long-term studies using pumps is that male animals are often required to be housed separately post-operatively, which could itself have adverse effects on the brain and/or behaviour 61. 


\section{Conclusions}

In summary, we find that continuous infusion of $\mathrm{MnCl}_{2}$ via mini-osmotic pumps does produce satisfactory tissue contrast without disrupting spatial learning and memory. However, at high cumulative doses, there is a risk of severe skin ulceration, which limits the useable imaging window. Study duration, age and health of animals, potential stress from surgery and/or repeated injections, and $\mathrm{MnCl}_{2}$ dose are all factors that must be balanced for a given study design.

\section{Acknowledgements}

The authors are grateful to Dr. Dana Poole and Dr. Louise van der Weerd for suggestions and feedback, Dr. Lindsay Cahill for comments on the manuscript, and Matthijs van Eede and Ben Darwin for computing support. This work was supported by the Canadian Institute for Health Research. DV was supported by a Restracomp Fellowship funded by the Hospital for Sick Children and an Ontario Graduate Scholarship funded by the Government of Ontario, Canada. RAG was supported by an Autism Speaks Fellowship. LQ was supported by a Restracomp Fellowship funded by the Hospital for Sick Children.

\section{References}

[1] I. Aoki, Y.-J. L. Wu, A. C. Silva, R. M. Lynch, A. P. Koretsky, In vivo detection of neuroarchitecture in the rodent brain using manganese-enhanced MRI., NeuroImage 22 (3) (2004) 1046-1059.

[2] A. C. Silva, N. A. Bock, Manganese-enhanced MRI: an exceptional tool in translational neuroimaging., Schizophrenia bulletin 34 (4) (2008) 595-604.

[3] A. P. Koretsky, A. C. Silva, Manganese-enhanced magnetic resonance imaging (MEMRI)., NMR in biomedicine 17 (8) (2004) 527-531.

[4] P. Lauterbur, Image Formation by Induced Local Interactions: Examples Employing Nuclear Magnetic Resonance, Nature 242 (5394) (1973) 190191.

[5] G. E. Mendonca-Dias, M H, P. Lauterbur, Paramagnetic contrast agents in nuclear magnetic resonance medical imaging, Vol. 13(4), 1983.

[6] T. J. Hallam, T. J. Rink, Agonists stimulate divalent cation channels in the plasma membrane of human platelets., FEBS letters 186 (2) (1985) $175-179$.

[7] Y. J. Lin, A. P. Koretsky, Manganese ion enhances T1-weighted MRI during brain activation: an approach to direct imaging of brain function., Magnetic Resonance in Medicine 38 (3) (1997) 378-388. 
[8] R. G. Pautler, In vivo, transsynaptic tracttracing utilizing manganeseenhanced magnetic resonance imaging (MEMRI), NMR in biomedicine 17 (8) (2004) 595-601.

[9] W. N. Sloot, J. Gramsbergen, Axonal transport of manganese and its relevance to selective neurotoxicity in the rat basal ganglia, Brain Research.

[10] A. Takeda, Y. Kodama, S. Ishiwatari, S. Okada, Manganese transport in the neural circuit of rat CNS., Brain research bulletin 45 (2) (1998) 149 152.

[11] X. Yu, Y. Z. Wadghiri, D. H. Sanes, D. H. Turnbull, In vivo auditory brain mapping in mice with Mn-enhanced MRI., Nature Neuroscience 8 (7) (2005) 961-968.

[12] O. Eschenko, S. Canals, I. Simanova, M. Beyerlein, Y. Murayama, N. K. Logothetis, Mapping of functional brain activity in freely behaving rats during voluntary running using manganese-enhanced MRI: implication for longitudinal studies., NeuroImage 49 (3) (2010) 2544-2555.

[13] R. G. Pautler, A. C. Silva, A. P. Koretsky, In vivo neuronal tract tracing using manganese-enhanced magnetic resonance imaging., Magnetic Resonance in Medicine 40 (5) (1998) 740-748.

[14] R. G. Pautler, A. P. Koretsky, Tracing odor-induced activation in the olfactory bulbs of mice using manganese-enhanced magnetic resonance imaging., NeuroImage 16 (2) (2002) 441-448.

[15] T. Watanabe, T. Michaelis, J. Frahm, Mapping of retinal projections in the living rat using high-resolution 3D gradient-echo MRI with Mn2+-induced contrast., Magnetic Resonance in Medicine 46 (3) (2001) 424-429.

[16] K. Matsuda, H. X. Wang, C. Suo, D. McCombe, M. K. Horne, W. A. Morrison, G. F. Egan, Retrograde axonal tracing using manganese enhanced magnetic resonance imaging., NeuroImage 50 (2) (2010) 366-374.

[17] R. G. Pautler, R. Mongeau, R. E. Jacobs, In vivo trans-synaptic tract tracing from the murine striatum and amygdala utilizing manganese enhanced MRI (MEMRI)., Magnetic Resonance in Medicine 50 (1) (2003) 33-39.

[18] P. R. Allegrini, C. Wiessner, Three-dimensional MRI of cerebral projections in rat brain in vivo after intracortical injection of $\mathrm{MnCl2}$., NMR in biomedicine 16 (5) (2003) 252-256.

[19] K. U. Szulc, J. P. Lerch, B. J. Nieman, B. B. Bartelle, M. Friedel, G. A. Suero-Abreu, C. Watson, A. L. Joyner, D. H. Turnbull, 4D MEMRI atlas of neonatal FVB/N mouse brain development., NeuroImage 118 (2015) 49-62. 
[20] G. Saar, N. Cheng, L. Belluscio, A. P. Koretsky, Laminar specific detection of APP induced neurodegeneration and recovery using MEMRI in an olfactory based Alzheimer's disease mouse model., NeuroImage 118 (2015) 183-192.

[21] J. P. van der Zijden, O. Wu, A. van der Toorn, T. P. Roeling, R. L. A. W. Bleys, R. M. Dijkhuizen, Changes in neuronal connectivity after stroke in rats as studied by serial manganese-enhanced MRI., NeuroImage 34 (4) (2007) 1650-1657.

[22] B. Zhang, K.-H. Chuang, C. Tjio, W. C. Chen, F.-S. Sheu, A. Routtenberg, Spatial memory training induces morphological changes detected by manganese-enhanced MRI in the hippocampal CA3 mossy fiber terminal zone., NeuroImage 128 (2016) 227-237.

[23] J. Scholz, R. Allemang-Grand, J. Dazai, J. P. Lerch, Environmental enrichment is associated with rapid volumetric brain changes in adult mice., NeuroImage 109 (2015) 190-198.

[24] L. R. Qiu, J. Germann, S. Spring, C. Alm, D. A. Vousden, M. R. Palmert, J. P. Lerch, Hippocampal volumes differ across the mouse estrous cycle, can change within 24 hours, and associate with cognitive strategies., NeuroImage.

[25] A. C. Silva, J. H. Lee, I. Aoki, A. P. Koretsky, Manganese-enhanced magnetic resonance imaging (MEMRI): methodological and practical considerations., NMR in biomedicine 17 (8) (2004) 532-543.

[26] A. W. Dobson, K. M. Erikson, M. Aschner, Manganese neurotoxicity., Annals of the New York Academy of Sciences 1012 (2004) 115-128.

[27] C. W. Olanow, ManganeseInduced Parkinsonism and Parkinson's Disease, Annals of the New York Academy of Sciences 1012 (1) (2004) 209-223.

[28] S. V. Chandra, G. S. Shukla, Role of iron deficiency in inducing susceptibility to manganese toxicity., Archives of toxicology 35 (4) (1976) 319-323.

[29] G. L. Wolf, L. Baum, Cardiovascular toxicity and tissue proton T1 response to manganese injection in the dog and rabbit., AJR. American journal of roentgenology 141 (1) (1983) 193-197.

[30] N. A. Bock, F. F. Paiva, A. C. Silva, Fractionated manganese-enhanced MRI., NMR in biomedicine 21 (5) (2008) 473-478.

[31] B. Grünecker, S. F. Kaltwasser, Y. Peterse, P. G. Sämann, M. V. Schmidt, C. T. Wotjak, M. Czisch, Fractionated manganese injections: effects on MRI contrast enhancement and physiological measures in C57BL/6 mice., NMR in biomedicine 23 (8) (2010) 913-921. 
[32] S. I. Mok, J. P. Munasinghe, W. S. Young, Infusion-based manganeseenhanced MRI: a new imaging technique to visualize the mouse brain., Brain structure \& function 217 (1) (2012) 107-114.

[33] M. R. Sepúlveda, T. Dresselaers, P. Vangheluwe, W. Everaerts, U. Himmelreich, A. M. Mata, F. Wuytack, Evaluation of manganese uptake and toxicity in mouse brain during continuous $\mathrm{MnCl} 2$ administration using osmotic pumps., Contrast media \& molecular imaging 7 (4) (2012) 426-434.

[34] D. S. Poole, N. Doorenweerd, J. J. Plomp, A. Mahfouz, M. J. T. Reinders, L. van der Weerd, Continuous infusion of manganese improves contrast and reduces side effects in manganese-enhanced magnetic resonance imaging studies., NeuroImage.

[35] O. Eschenko, S. Canals, I. Simanova, N. K. Logothetis, Behavioral, electrophysiological and histopathological consequences of systemic manganese administration in MEMRI., Magnetic resonance imaging 28 (8) (2010) 1165-1174.

[36] S. J. Jackson, R. Hussey, M. A. Jansen, G. D. Merrifield, I. Marshall, A. MacLullich, J. L. W. Yau, T. Bast, Manganese-enhanced magnetic resonance imaging (MEMRI) of rat brain after systemic administration of $\mathrm{MnCl2}$ : Hippocampal signal enhancement without disruption of hippocampus-dependent behavior, Behavioural brain research 216 (1) (2011) 293-300.

[37] J. Nam, K. Kim, Abnormal motor function and the expression of striatal dopamine D2 receptors in manganese-treated mice., Biological \& pharmaceutical bulletin 31 (10) (2008) 1894-1897.

[38] E. H. Owen, S. F. Logue, D. L. Rasmussen, J. M. Wehner, Assessment of learning by the Morris water task and fear conditioning in inbred mouse strains and F1 hybrids: implications of genetic background for single gene mutations and quantitative trait loci analyses., Neuroscience 80 (4) (1997) 1087-1099.

[39] N. A. N. Bock, B. J. B. Nieman, J. B. J. Bishop, R. R. M. Henkelman, In vivo multiple-mouse MRI at 7 Tesla., Magnetic Resonance in Medicine 54 (5) (2005) 1311-1316.

[40] J. J. Dazai, S. S. Spring, L. S. L. Cahill, R. M. R. Henkelman, Multiplemouse neuroanatomical magnetic resonance imaging., Journal of Visualized Experiments (48) (2011) -.

[41] B. Belaroussi, J. Milles, S. Carme, Y. M. Zhu, H. Benoit-Cattin, Intensity non-uniformity correction in MRI: Existing methods and their validation, Medical image analysis 10 (2) (2006) 234-246. 
[42] J. G. Sled, A. P. Zijdenbos, A. C. Evans, A nonparametric method for automatic correction of intensity nonuniformity in MRI data., Medical Imaging, IEEE Transactions on 17 (1) (1998) 87-97.

[43] D. L. Collins, P. Neelin, T. M. Peters, A. C. Evans, Automatic 3D intersubject registration of MR volumetric data in standardized Talairach space., Journal of computer assisted tomography 18 (2) (1994) 192-205.

[44] M. M. Chakravarty, P. Steadman, M. C. Eede, R. D. Calcott, V. Gu, P. Shaw, A. Raznahan, D. L. Collins, J. P. Lerch, Performing labelfusionbased segmentation using multiple automatically generated templates, Human Brain Mapping 34 (10) (2013) 2635-2654.

[45] A. E. Dorr, J. P. Lerch, S. Spring, N. Kabani, R. M. Henkelman, High resolution three-dimensional brain atlas using an average magnetic resonance image of 40 adult C57Bl/6J mice., NeuroImage 42 (1) (2008) 60-69.

[46] J. P. Lerch, J. B. Carroll, S. Spring, L. N. Bertram, C. Schwab, M. R. Hayden, R. M. Henkelman, Automated deformation analysis in the YAC128 Huntington disease mouse model., NeuroImage 39 (1) (2008) 32-39.

[47] J. P. Lerch, J. G. Sled, R. M. Henkelman, MRI phenotyping of genetically altered mice, Magnetic Resonance Neuroimaging.

[48] A. Kuznetsova, P. B. Brockhoff, R. Haubo Bojesen Christensen, lmerTest: Tests in Linear Mixed Effects Models. R package version 2.0-32.

[49] C. R. Genovese, N. A. Lazar, T. Nichols, Thresholding of statistical maps in functional neuroimaging using the false discovery rate., NeuroImage 15 (4) (2002) 870-878.

[50] J. C. Pinheiro, D. M. Bates, Mixed-effects models in S and S-PLUS, 2000th Edition, Springer.

[51] T. M. Therneau, P. M. Grambsch, A Package for Survival Analysis in S. version 2.38 .

[52] T. M. Therneau, P. M. Grambsch, Modeling survival data: extending the Cox model (2000).

[53] H. P. Rang, J. M. Ritter, R. J. Flower, G. Henderson, Rang \& Dale's Pharmacology: With student consult online access (2014).

[54] C. E. Gavin, K. K. Gunter, T. E. Gunter, Manganese and calcium transport in mitochondria: implications for manganese toxicity., Neurotoxicology 20 (2-3) (1999) 445-453.

[55] C. E. Gavin, K. K. Gunter, T. E. Gunter, Manganese and calcium efflux kinetics in brain mitochondria. Relevance to manganese toxicity., The Biochemical journal 266 (2) (1990) 329-334. 
[56] S. A. Perrine, F. Ghoddoussi, K. Desai, R. J. Kohler, A. T. Eapen, M. J. Lisieski, M. Angoa-Perez, D. M. Kuhn, K. E. Bosse, A. C. Conti, D. Bissig, B. A. Berkowitz, Cocaine-induced locomotor sensitization in rats correlates with nucleus accumbens activity on manganese-enhanced MRI., NMR in biomedicine 28 (11) (2015) 1480-1488.

[57] S. P. Brooks, S. B. Dunnett, Tests to assess motor phenotype in mice: a user's guide., Nature Reviews Neuroscience 10 (7) (2009) 519-529.

[58] D. Glynn, C. J. Drew, K. Reim, N. Brose, A. J. Morton, Profound ataxia in complexin I knockout mice masks a complex phenotype that includes exploratory and habituation deficits., Human molecular genetics 14 (16) (2005) 2369-2385.

[59] R. J. Carter, L. A. Lione, T. Humby, L. Mangiarini, A. Mahal, G. P. Bates, S. B. Dunnett, A. J. Morton, Characterization of Progressive Motor Deficits in Mice Transgenic for the Human Huntington's Disease Mutation, The Journal of neuroscience : the official journal of the Society for Neuroscience 19 (8) (1999) 3248-3257.

[60] L. Shallcross, S. Ritchie, E. Harberts, A. Tammaro, J. Gaitens, A. A. Gaspari, Manganese oxidation state as a cause of irritant patch test reactions., Dermatitis : contact, atopic, occupational, drug 25 (2) (2014) 66-71.

[61] J. Liu, K. Dietz, J. M. DeLoyht, X. Pedre, D. Kelkar, J. Kaur, V. Vialou, M. K. Lobo, D. M. Dietz, E. J. Nestler, J. Dupree, P. Casaccia, Impaired adult myelination in the prefrontal cortex of socially isolated mice., Nature Neuroscience 15 (12) (2012) 1621-1623. 